\title{
Pathophysiologic Role of Molecules Determining Arteriovenous Differentiation in Adult Life
}

\author{
Fang Liu ${ }^{a}$ Zhong Yao ${ }^{b}$ Ping Lüc Qi-Bin Jiao ${ }^{d}$ Qin Liu ${ }^{c}$ Hong-Xiao $\mathrm{Wu}^{c}$ \\ Yun You ${ }^{c}$ Susumu Minamisawa ${ }^{e}$ \\ aNuclear Medicine Department, Union Hospital, Tongji Medical College, Huazhong University of Science and \\ Technology, Wuhan, China; ${ }^{b}$ Donnelly Centre for Cellular and Biomolecular Research, University of Toronto, \\ Toronto, ON, Canada; 'Vascular Surgery Department, Union Hospital, Tongji Medical College, Huazhong University \\ of Science and Technology, Wuhan, China; 'Department of Cardiology, The Affiliated Hospital of Hangzhou Normal \\ University, Institute of Ageing Research, School of Medicine, Hangzhou Normal University, Hangzhou, China; \\ eDepartment of Cell Physiology, The Jikei University School of Medicine, Tokyo, Japan
}

\section{Keywords}

Vascular development - Vascular remodeling • Identity · Eph-B4 · Ephrin-B2

\begin{abstract}
The structural differences between arteries and veins are genetically predetermined. Vascular identity markers, the molecular markers specific to veins and arteries, determine the differential development of vessels during embryogenesis and their expression persists in adult vessels. It is revealed that they can be reactivated under various pathophysiologic conditions even after vessel differentiation. Thus, once considered as quiescent in adults, vascular identity markers may actually play significant roles in vascular remodeling. Manipulation of vascular identity and the underlying molecular mechanisms might be a novel strategy to improve vascular remodeling for clinical application.
\end{abstract}

\section{Introduction}

The structural differences between arteries and veins are genetically predetermined by molecules through controlling the fate of blood vessels during embryogenesis. Some of them are persistently expressed during adulthood as specific identity markers of arteries and veins [1, 2]. New evidence reveals that even after vessel differentiation, vascular identity markers still have the potential to function under pathophysiologic conditions (including surgical procedures) (Fig. 1). This is of particular significance when referring to their roles in potential therapeutic applications. In this review, we will focus on arterial and venous identity markers and their specific roles in some pathophysiologic processes.

\section{Vasculogenesis and Angiogenesis}

Formation of a vascular system with proper organizational structure is critical for embryo development and survival. Vasculogenesis and angiogenesis are 2 succes-

\footnotetext{
Dr. Ping Lü

Tongji Medical College, Huazhong University of Science and Technology Vascular Surgery Department, Union Hospital

Jiefang Dadao Ave 1277, Wuhan 430022 (China)

lvping2013@aliyun.com
} 
sive processes through which blood vessels are formed during embryonic development. Vasculogenesis is a process of in situ differentiation of angioblasts and endothelial cells (ECs) from mesenchyme and their coalescence into tubes of primary vascular plexus. Expansion of this primitive vascular system occurs through angiogenesis, either sprouting angiogenesis or intussusception angio-

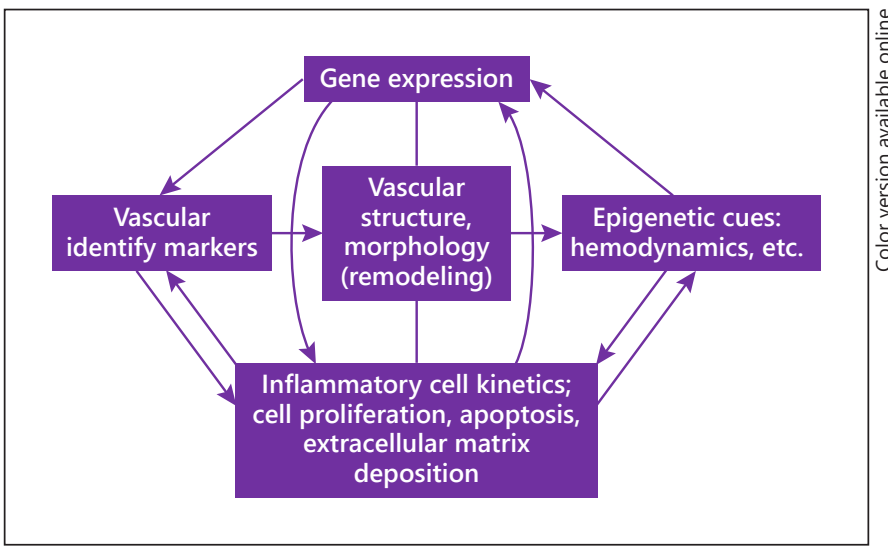

Fig. 1. Vascular identity markers are involved in vascular remodeling. The dynamic interplay between gene expression, vascular identity markers, vascular structure, epigenetic cues (e.g., hemodynamics), and the biologic response of the vascular wall construct a regulatory network of vascular remodeling. genesis. Through these distinct angiogenesis processes, the primary vascular plexus is remodeled into a hierarchical vascular tree with properly branched arteries, capillaries, and veins. Upon initiation of blood flow, the primitive vascular plexus exhibits a remarkable degree of plasticity, indicating that not only the vessel identity but also the global pattern of developing arterial-venous networks is remodeled by blood flow [3].

\section{Arteriovenous Specification}

Vascular specification is genetically determined early during the course of development. In this complex developmental program, correct spatial and temporal expression of a diversity of genes is orchestrated by a large set of transcription factors. Endothelial progenitors expressing several endothelial-specific markers can be detected early in embryo development. They are further differentiated to acquire specific arterial and venous properties. The signaling pathways involved in arterial and venous determination are hierarchically organized [4] (Fig. 2).

\section{Arterial Specification}

At the top of the arterial specification program, sonic hedgehog triggers the expression of the vascular endothelial growth factor (VEGF), which, at its high concentration, can promote the activation of Notch signaling [5].
Fig. 2. Signaling pathways involved in arteriovenous specification. Shh lies at the top of arterial specification and triggers the expression of VEGF, while at high concentrations, promoting Notch signaling activation. Wnt and other transcription factors, such as Foxc1, Foxc2, and Sox17, cooperate to activate Notch signaling and determine arterial fate. Instead, vein progenitors are exposed to low VEGF concentrations and express COUP-TFII transcription factor, which promotes venous identity by suppressing Notch, Jag1 signaling, and ephrinB2. BRG1, brahma-related gene 1; COUPTFII, chicken ovalbumin upstream promoter transcription factor II; Dll, Delta-like; Eph, erythropoietin-producing hepatocellular; Flk, fetal liver kinase; Flt, Fms-related tyrosine kinase; Foxc, Forkhead box C; grl, notch-gridlock; Hey, Hes-related family BHLH transcription factor with YRPW motif; JAG, gap junction alpha; NP, neuropilin; Raf, rapidly accelerated fibrosarcoma; Shh, sonic hedgehog; Sox, sex determining region Y-box; VEGF, vascular endothelial growth factor; Wnt, wingless/integrated.

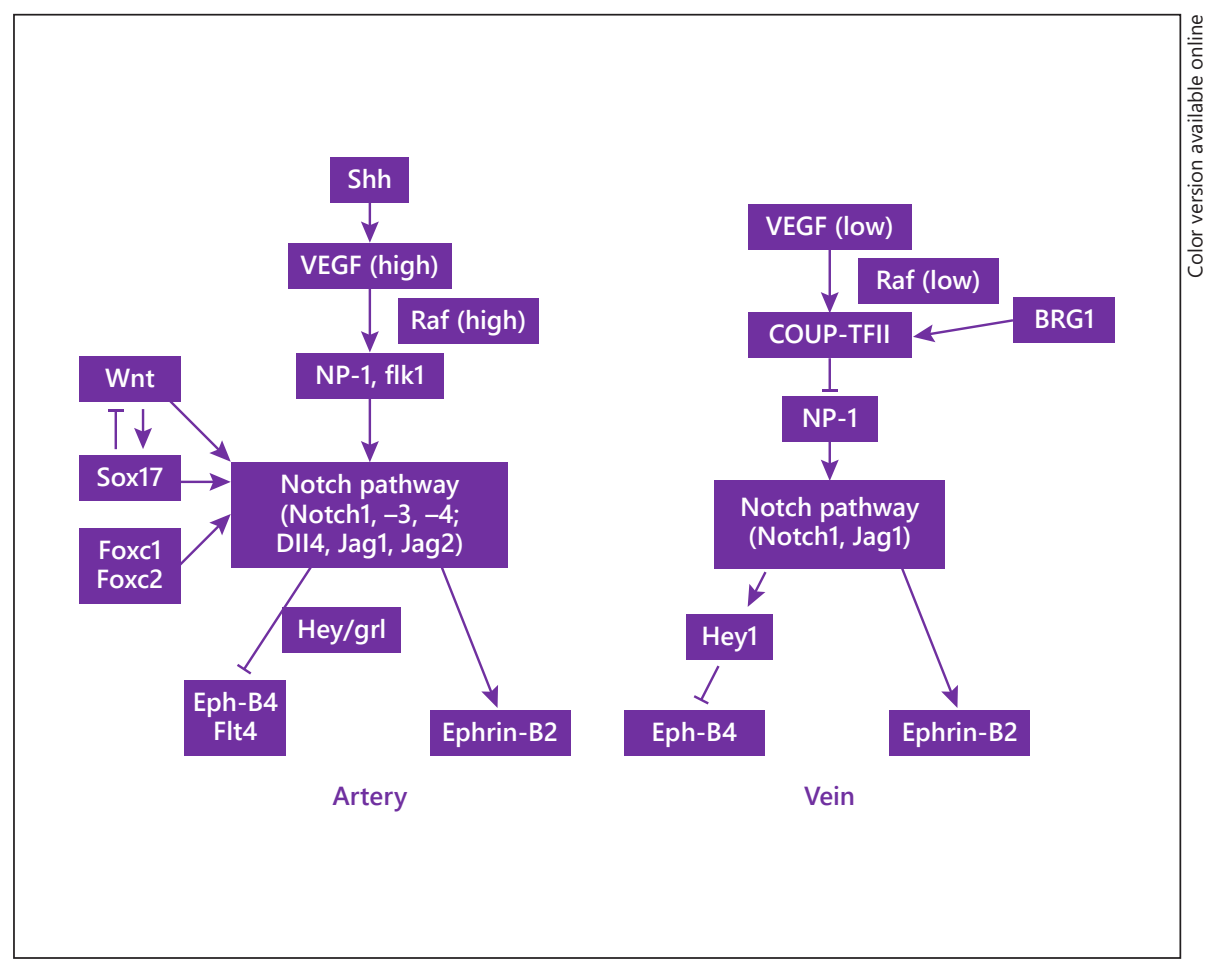


Besides VEGF, Wnt signaling and other transcription factors such as Foxc1, Foxc2, and Sox17 converge into the Notch pathway and induce arterial differentiation of ECs [6-8], whereas vein progenitors are determined through exposure to low VEGF concentration followed by expression of chicken ovalbumin upstream promoter transcription factor II (COUP-TFII) that inhibits Notch signaling so as to promote venous specification [9]. Several research studies suggested that there is an antagonistic cross talk between VEGF-activated intracellular signaling pathways [10-12]. A VEGF-dependent enhancer of Delta-like 4 (Dll4) has been recently described, which is a minimal region that can drive arterial expression of Dll4 [13].

\section{Venous Specification}

Identification of COUP-TFII provides the evidence of a direct transcriptional induction during venous differentiation. COUP-TFII has been found to be expressed only in venous and not in arterial ECs. You et al. [14] elegantly demonstrated that COUP-TFII has a cell-autonomous function in venous specification, and COUP-TFII mutant cells show a partial reduction of venous markers but a strong upregulation of several arterial markers. On the contrary, endothelial-specific overexpression of COUPTFII leads to a lethal vascular phenotype through hampering the expression of several arterial markers and simultaneously acquiring the venous marker erythropoietin-producing hepatocellular (Eph)-B4 by arteries [14]. The mechanism underlying the action of COUP-TFII exerts an inhibitory effect on Notch signaling and, therefore, promotes venous differentiation by repressing arterial specification [9]. It is revealed that brahma-related gene 1 (BRG1) promotes COUP-TFII expression by binding conserved regulatory elements within the COUPTFII promoter. BRG1 is a SWI/SNF member ATPase, which serves to remodel chromatin and allows the promoter accessible to transcriptional machinery. In case of BRG1 inactivation, arterial markers will be induced in veins [15].

\section{Notch Signaling Pathway}

Components of the Notch signaling pathway are the first group of genes to be implicated in arterial endothelial specification [16]. As large transmembrane receptors, Notch proteins govern fate decisions in numerous cell types, angiogenesis, and vascular homeostasis during both embryonic and adult stages. When bound to the transmembrane ligands Dll or Jagged (JAG), Notch receptors are activated through cleavage and the intracel-

Vascular Identity Markers Are Involved in Vascular Pathophysiology lular domain of the processed Notch receptor translocates into the nucleus. It interacts with the recombination signal binding protein for immunoglobulin Kappa J region to form a transactivation complex and then induces target gene expression [16] There are 4 Notch receptors (Notch1-4) and 5 ligands (JAG1 and 2 and Dll1, 3, and 4) expressed in mammals. Although early Notch activation can bestow positional determination, this does not irrevocably commit cells to an arterial fate. Lineage-tracing studies reveal that Notch-activated cells initially and positionally committed to the dorsal aorta can later become venous tissue by de- or transdifferentiation [17].

\section{Ephs and Ephrins}

As the largest subfamily of growth factor receptors, Eph receptor tyrosine kinases (RTKs) utilize ephrins, similarly with multiple isoforms, as their ligands [18]. Unlike many ligands for other receptor tyrosine kinases, ephrins must be membrane tethered in order to activate their Eph receptors. Ephrins can be divided into 2 subclasses, ephrin-A and ephrin-B, according to their linkage to the cell membrane. Ephrin-B ligands primarily interact with the B subset of Eph receptors, which consist of at least 5 members (Eph-B1-4 and Eph-B6) [19]. Interactions between ephrin-B and Eph-B apparently activate bidirectional signaling, including activation of the intracellular RTK domain of Eph-B, which also involves tyrosine phosphorylation [20].

In view of the vascular defects observed in embryonic mice bearing null mutations in ephrin-B/Eph-B (e.g., inflated or extended pericardium, abnormal cardinal veins or dorsal aorta, and pale yolk sacs with few blood vessels) [21], much attention of researchers has been attracted to the roles of ephrin-B2 and its cognate receptor Eph-B4 in cardiovascular development. Moreover, a distinctively reciprocal pattern of ephrin-B2 and Eph-B4 distribution within the developing vasculature has been revealed, that is, ephrin-B2 distinctively in the endothelium of primordial arterial vessels, while Eph-B4 in the endothelium of primordial venous vessels [22]. It has been confirmed that ephrin-B2 is a marker of arterial endothelium and smooth muscle and its expression persists in adult vessels. Conversely, Eph-B4 is a marker of venous cells and also persistently expressed in adult vessels $[1,2]$.

\section{Hemodynamic Forces in Vascular Development}

During embryonic development, molecular markers that distinguish arteries from veins are expressed before the onset of blood circulation [23]. However, hemodynamic forces imparted by blood flow play important roles 
Table 1. Arterial and venous identity markers already identified

\begin{tabular}{|c|c|c|c|}
\hline Marker & Year & Research & Model \\
\hline \multicolumn{4}{|l|}{ Arterial } \\
\hline ALK1 & 2003 & Seki et al. [29] & Mouse \\
\hline CD44 & 2004 & Fischer et al. [30] & Mouse \\
\hline Connexin-37 & 2005 & Shin et al. [31] & Mouse \\
\hline Connexin-40 & 2002 & Mukouyama et al. [32] & Mouse \\
\hline Dll4 & 2000 & Shutter et al. [33] & Mouse \\
\hline Ephrin-B2 & 1998 & Wang et al. [1] & Mouse \\
\hline IGFB-5P & 2005 & Shin et al. [31] & Mouse \\
\hline NP1 & 2002 & Mukouyama et al. [32] & Mouse \\
\hline Notch1, 3, 4 & 2000,2001 & Yoshikawa et al. [34]; Villa et al. [35] & Mouse \\
\hline UNC5B & 2004 & Lu et al. [36] & Mouse and zebrafish \\
\hline bHLH transcription factors Heyl and Hey2 & 1999 & Leimeister et al. [37] & Mouse \\
\hline GJA5 & 1982 & Spagnoli et al. [41] & Rabbit \\
\hline \multicolumn{4}{|l|}{ Venous } \\
\hline APJ & 1999 & Devic et al. [42] & Mouse \\
\hline COUP-TFII & 2005 & You et al. [14] & Mouse \\
\hline Eph-B4 & 1998 & Wang et al. [1] & Mouse \\
\hline NP2 & 2001 & Herzog et al. [43] & Chick \\
\hline Endomucin & 1999 & Morgan et al. [44] & Mouse \\
\hline VEGFR3/FLT4 & 1995 & Kaipainen et al. [45] & Tissues from mouse and human \\
\hline TIE2 & 2001 & Moyon et al. [46] & Avian \\
\hline
\end{tabular}

ALK1, activin receptor-like kinase 1; CD44, classification determinant 44; Dll4, Delta-like 4; DEPP, decidual protein induced by progesterone; IGFB-5P, insulin-like growth factor binding protein-5 protease; NP, neuropilin; UNC5B, unc-5 netrin receptor B; bHLH, basic helix-loop-helix; JAG, Jagged; RGS5, regulator of G protein signaling 5; SOX, sex determining region Y-box; aSMA, a-smooth muscle actin; GJA5, gap junction protein alpha 5; APJ, apelin receptor; COUP-TFII, chicken ovalbumin upstream promoter transcription factor II; ; VEGFR3/FLT4, vascular endothelial growth factor receptor 3; TIE2, tyrosine kinase with immune globulin and EGF homology domains 2 .

in embryonic vasculature development. In mature vasculature, different blood flow regimes can induce distinct genetic programs and vessel identity plasticity [3].

Thoma first observed the relationships between mechanical stimuli and vessel form and function in the chick embryo. Thoma's conclusions can be stated in another way; that is, the geometric properties of vessels are optimized to the applied forces and serve to normalize the mechanical stresses $[24,25]$. There are multifarious mechanisms of mechanosensation and mechanotransduction involved in transducing hemodynamic signals into biochemical responses, which have been discussed in another review [26]. Embryonic and early postnatal ECs must sense and respond to blood flow to properly shape the developing vasculature. Although arterial and venous specification has been initially hard-wired in the vertebrate em- bryo, blood flow plays an important role in maintaining these identities and unmasking plasticity when appropriate. In addition, hemodynamic forces also play a critical role in maintenance of dorsal aorta-derived definitive hematopoietic stem cells in zebrafish embryos [27]. In chick embryo yolk sac, alteration of blood flow can cause changes in the global gene expression profile and de novo expression of arterial genes within venous tracts. Moreover, ECs with expression of the arterial-specific genes ephrinB2 or neuropilin-1 can still be incorporated into the venous system in response to this blood flow change [3]. During cardiac cycles in the early mouse embryo, differences in both the levels of shear stress and the flow rates between arteries and veins may be sufficient to differentially regulate COUP-TFII expression such that COUPTFII expression would only be present in veins [28]. 


\section{Arterial and Venous Identity Markers Already Identified}

We list vascular identity markers of interest in Table 1 , which contains 23 arterial molecular markers [1, 8, 29$41]$ and 7 venous molecular markers [1, 14, 42-46]. Notably, some membrane proteins functioning in certain membrane structures, such as lipid rafts and caveolae, are also involved in vessel identity determination [47].

\section{Plasticity of Vascular Identity Markers and Potential Therapeutic Applications}

Once thought to be quiescent in adults, vascular identity markers may actually play a significant role in vascular remodeling and their expression can also change. Our work and results from other laboratories indicate that vascular identity markers appear to be plastic upon surgical treatment. In addition, they are also involved in other pathologic conditions such as tumors and pulmonary arterial hypertension (PAH) [48-51]. Particularly, activation of Eph-B4 may promote patency of vein grafts and arteriovenous fistula (AVF) due to the prevention of neointimal hyperplasia $[52,53]$. In contrast, use of a soluble form of Eph-B4 can reduce tumor angiogenesis and growth [54]. Moreover, pharmacological inhibition of Notch3 reverses hypoxic PAH in mice [51]. Thus, regulation of vascular identity and its underlying molecular mechanisms might be a new path to manipulating vascular remodeling in adults.

\section{Vein Grafts}

Human vein graft adaptation in the arterial environment is largely associated with loss of the venous identity marker Eph-B4, without stimulation of the arterial identity marker ephrin-B2. This adaptation is characterized by both sustained downregulation of Eph-B4 expression and transient upregulation of VEGF-A expression followed by its downregulation. The underlying mechanism of these changes was revealed with an in vitro adult EC model. Thus, the early phase increase in VEGF-A inhibits the expression of Eph-B4 and upregulates the expression of Dll4 (a Notch ligand), but without stimulating its downstream signaling events such as Notch activation or ephrin-B2 expression in these adult ECs. These results are consistent with the effects of blocking the VEGF/COUPTFII-Notch signaling-Eph-B4/ephrin-B2 pathway in adult ECs [55]. Therefore, vein grafts lose their venous identity markers without acquiring arterial identity. Activation of Eph-B4 via ligands or expression of constitu-

Vascular Identity Markers Are Involved in Vascular Pathophysiology tively active Eph-B4 inhibits venous wall thickening. Conversely, reduction of Eph-B4 signaling is associated with increased venous wall thickness of vein grafts [56]. It is further confirmed that activation of Eph-B4 signaling also stimulates caveolin-1 phosphorylation during vein graft adaptation, and caveolin-1 subsequently executes its Eph-B4-induced function on vein graft wall thickness via modulation of endothelial nitric oxide synthase function [53]. These results indicate that Eph-B4 is active in adult veins and regulates venous remodeling.

$A V F$

As the preferred method of hemodialysis access, autogenous AVF presents poor patency and low maturation. The situation in the venous segment of an AVF is dramatically different from that in a vein graft. We have explored the remodeling pattern of the venous segment of the carotid-jugular shunt at a late stage ( 15 weeks) after operation in adult rats. Our results revealed that the venous identity marker Eph-B4 was lost, but the arterial identity markers ephrin-B2 and regulator of G-protein signaling 5 (RGS5) were gained in the jugular segment of the carotid-jugular shunt. The expression of these 2 arterial identity markers was further strengthened in the pulmonary artery in shunted rats compared with controls. The jugular segment of the carotid-jugular shunt underwent significant intimal hyperplasia with strong expression of smooth muscle cell (SMC) markers. It also presented a distinct transcriptional profile including significant upregulation of 5 arterial markers as compared to the sham-operated jugular vein, among which RGS5 is exactly the gene with the most change (10.14-fold) tested by microarray experiments [48]. In another mouse study, at 3 weeks after surgery, the venous limb of the infrarenal aortocaval fistula gained dual arterial/venous identity markers (i.e., ephrin-B2/Eph-B4). Promoting this AVF to preserve venous identity (Eph-B4) with ephrin-B2 did prevent excessive wall thickening and promote AVF patency [52].

\section{Patch Angioplasty}

Studies of rat aortic and inferior vena cava patch models indicate that pericardial patches obtain the identity of the vessel in which they are placed; that is, pericardial patches express the arterial marker ephrin-B2 in arterial environments, whereas pericardial patches express the venous marker Eph-B4 in venous environments [57, 58]. Further study demonstrates that atorvastatin can regulate neointimal growth after pericardial patch angioplasty in the arterial environment by regulating the pathway in- 
volved in ephrin-B2 expression [59]. Interestingly, in a rat model of polyester patches implanted into the aorta or inferior vena cava, polyester patches healed by infiltration of host arterial or venous progenitor cells depending on the site of implantation. Moreover, when these synthetic patches were treated with AVF, they would have decreased neointimal thickness with neointimal ECs expressing the arterial identity markers ephrin-B2 and Notch4, in addition to the venous identity markers EphB4 and COUP-TFII (dual arterial-venous identity) [60]. These data suggest that synthetic patches heal by acquisition of identity of their environment.

\section{Revascularization of Ischemic Tissues}

Some arterial-specific markers are also involved in angiogenesis. It was observed that collateral blood flow was reduced after femoral artery occlusion in 12-week-old transgenic mice with induced EC-specific expression of mutants of the arterial identity marker gap junction alpha 5 (GJA5). These GJA5 mutants had fewer and smaller collateral arterioles, which well accounted for the perfusion deficit. Furthermore, a reduced outward remodeling response was also observed in mesenteric arteries in these GJA5 mutant mice when chronically exposed to increased blood flow, implying that GJA5 might be involved as a positive modulator in adaptation to flow. The reduced number of preexisting collateral arterioles further suggests that GJA5 might play an important role in the formation of native collaterals [61]. Other effective therapies involving clarification of vascular identity for treating peripheral arterial disease have also been developed or are in development $[62,63]$.

\section{Tumor Blood Vessels}

Tumor blood vessels also express Eph-B4 and ephrinB2, which are indeed associated with mammary gland carcinogenesis and tumor progression. Increasing evidence implicates Eph/ephrin interactions do occur in cancer. It has been demonstrated that tumor angiogenesis and growth were reduced by the use of a neutralizing protein, the soluble form of Eph-B4 [54], and retinal neovascularization was similarly reduced by either soluble EphB4 or soluble ephrin-B2 [64]. Moreover, the induction of ephrin-B2 expression is observed during development of Kaposi sarcoma and hepatocarcinoma [50]. Vascular tumors, hemangioma and angiosarcoma, originating from endothelium are closely related to the signaling pathways of involved vascular identity markers. Expression of Tie2, JAG1, Notch4, and Eph-B3 is increased in proliferating hemangioma. The potential role of Eph-B4 in the patho- genesis of angiosarcoma has been suggested by high level of membranal Eph-B4 $[65,66]$. These evidences prove the potential of targeting vascular identity markers for treating cancer and pathologic angiogenesis.

\section{PAH}

The involvement of Notch receptor in controlling proliferation of SMCs and maintaining their undifferentiated state has been identified. Research indicates that Notch3 is a marker for PAH disease severity. Overexpression of Notch3 in small pulmonary artery SMCs has been shown in human pulmonary hypertension. Moreover, the abundance of Notch3 protein in the lung is correlated with the severity of PAH both in human and in rodent models of hypoxia-induced or monocrotaline-induced $\mathrm{PAH}$. Results further show that Notch3 is primarily involved in pulmonary vascular remodeling rather than in affecting pulmonary vasoreactivity [51]. As compared to placebo treatment, hypoxic PAH mice with pharmacological Notch3 inhibition presented significant reductions in right ventricular systolic pressures, normal-appearing pulmonary vessels with rarely detected medial thickening or vessel occlusion, less proliferating SMCs but increased apoptotic cells in the remodeled walls of small pulmonary arteries, and regression of right ventricular hypertrophy. Angiograms demonstrated that PAH mice with pharmacological Notch3 inhibition showed a patent distal pulmonary vascular tree, whereas control PAH mice showed blunting of the pulmonary vasculature with the absence of peripheral artery filling. Furthermore, it was shown that mice with homozygous deletion of Notch3 did not develop PAH in response to hypoxic stimulation [51].

\section{Other Vascular Pathophysiologic Conditions}

Vascular identity markers have also been found to be involved in other vascular physiopathologic conditions, such as hypertension (RGS) [67], vascular phenotypic remodeling in hyperhomocysteinemia (ephrin-B2 and Eph-B4) [68], brain arteriovenous malformation (VEGF, Notch, ephrin-B2, and Eph-B4) [69, 70], and development and maintenance of the uteroplacental vascular network (ephrin-B2 and Eph-B4) [71].

\section{Summary}

Vascular identity markers determine the differential development of arteries and veins. These markers once thought to be quiescent in adults actually are involved in 
vascular physiopathologic processes. Manipulation of these potential therapeutic targets might be a novel strategy to improve vascular remodeling in adults.

\section{Acknowledgements}

The authors are grateful to Dr. Daisuke Shimura, Dr. Ken Uesugi, Dr. Ichige Kajimura, Dr. Eriko Omori, and Dr. Gaku Nakai from the Center for Advanced Biomedical Sciences (TWIns), Waseda University, Tokyo, Japan, and Dr. Yoichiro Kusakari from the Department of Cell Physiology, the Jikei University School of Medicine, Tokyo, Japan, for skillful assistance in experiments.

\section{Disclosure Statement}

The authors have no conflicts of interest to declare.

\section{Funding Sources}

This work was supported by grants from the Ministry of Education, Culture, Sports, Science and Technology of Japan (S.M.), the Vehicle Racing Commemorative Foundation (S.M.), the Jikei University Graduate Research Fund (S.M.), the Miyata Cardiology Research Promotion Foundation (S.M.), the Natural Science Foundation of China (81670512 to P.L. and 81101042 to F.L.), and the Natural Science Foundation of Hubei Province, China (2016CFB378 to P.L.).

\section{Author Contributions}

P.L. prepared the figures; P.L. and F.L. drafted the manuscript; P.L., F.L., Z.Y., Q.-B.J., Q.L., H.-X.W., Y.Y., and S.M. edited the manuscript; P.L., F.L., Z.Y., Q.-B.J., Q.L., H.-X.W., Y.Y., and S.M. approved the final version of the manuscript.

\section{References}

1 Wang HU, Chen ZF, Anderson DJ. Molecular distinction and angiogenic interaction between embryonic arteries and veins revealed by ephrin-B2 and its receptor Eph-B4. Cell. 1998 May;93(5):741-53.

2 Gale NW, Baluk P, Pan L, Kwan M, Holash J, DeChiara TM, et al. Ephrin-B2 selectively marks arterial vessels and neovascularization sites in the adult, with expression in both endothelial and smooth-muscle cells. Dev Biol. 2001 Feb;230(2):151-60.

3 le Noble F, Moyon D, Pardanaud L, Yuan L, Djonov V, Matthijsen R, et al. Flow regulates arterial-venous differentiation in the chick embryo yolk sac. Development. 2004 Jan; 131(2):361-75.

4 Gauvrit S, Villasenor A, Strilic B, Kitchen P, Collins MM, Marín-Juez R, et al. HHEX is a transcriptional regulator of the VEGFC/ FLT4/PROX1 signaling axis during vascular development. Nat Commun. 2018 Jul; 9(1):2704.

5 Lawson ND, Vogel AM, Weinstein BM. sonic hedgehog and vascular endothelial growth factor act upstream of the Notch pathway during arterial endothelial differentiation. Dev Cell. 2002 Jul;3(1):127-36.

6 Morini MF, Dejana E. Transcriptional regulation of arterial differentiation via Wnt, Sox and Notch. Curr Opin Hematol. 2014 May; 21(3):229-34.

7 Ye X, Wang Y, Cahill H, Yu M, Badea TC, Smallwood PM, et al. Norrin, frizzled-4, and Lrp5 signaling in endothelial cells controls a genetic program for retinal vascularization. Cell. 2009 Oct 16;139(2):285-98.

8 Corada M, Orsenigo F, Morini MF, Pitulescu ME, Bhat G, Nyqvist D, et al. Sox17 is indispensable for acquisition and maintenance of arterial identity. Nat Commun. 2013;4:2609.
9 Chen X, Qin J, Cheng CM, Tsai MJ, Tsai SY. COUP-TFII is a major regulator of cell cycle and Notch signaling pathways. Mol Endocrinol. 2012 Aug;26(8):1268-77.

10 Hong CC, Kume T, Peterson RT. Role of crosstalk between phosphatidylinositol 3-kinase and extracellular signal-regulated kinase/mitogen-activated protein kinase pathways in artery-vein specification. Circ Res. 2008 Sep;103(6):573-9.

11 Ren B, Deng Y, Mukhopadhyay A, Lanahan AA, Zhuang ZW, Moodie KL, et al. ERK1/2Akt1 crosstalk regulates arteriogenesis in mice and zebrafish. J Clin Invest. $2010 \mathrm{Apr}$; 120(4):1217-28.

12 Geudens I, Coxam B, Alt S, Gebala V, Vion AC, Meier K, et al. Artery-vein specification in the zebrafish trunk is pre-patterned by heterogeneous Notch activity and balanced by flow-mediated fine-tuning. Development. 2019 Aug;146(16):dev181024.

13 Wythe JD, Dang LT, Devine WP, Boudreau E, Artap ST, He D, et al. ETS factors regulate Vegf-dependent arterial specification. Dev Cell. 2013 Jul;26(1):45-8.

14 You LR, Lin FJ, Lee CT, DeMayo FJ, Tsai MJ, Tsai SY. Suppression of Notch signalling by the COUP-TFII transcription factor regulates veinidentity.Nature.2005 May;435(7038):98104.

15 Davis RB, Curtis CD, Griffin CT. BRG1 promotes COUP-TFII expression and venous specification during embryonic vascular development. Development. 2013 Mar; 140(6):1272-81.

16 Mack JJ, Iruela-Arispe ML. NOTCH regulation of the endothelial cell phenotype. Curr Opin Hematol. 2018 May;25(3):212-8.
17 Saha N, Robev D, Mason EO, Himanen JP, Nikolov DB. Therapeutic potential of targeting the Eph/ephrin signaling complex. Int J Biochem Cell Biol. 2018 Dec;105:123-33.

$18 \mathrm{Wu}$ Z, Ashlin TG, Xu Q, Wilkinson DG. Role of forward and reverse signaling in Eph receptor and ephrin mediated cell segregation. Exp Cell Res. 2019 Aug;381(1):57-65.

19 Quillien A, Moore JC, Shin M, Siekmann AF, Smith T, Pan L, et al. Distinct Notch signaling outputs pattern the developing arterial system. Development. 2014 Apr;141(7):1544-52.

20 Wei Q, Liu J, Wang N, Zhang X, Jin J, ChinSang I, et al. Structures of an Eph receptor tyrosine kinase and its potential activation mechanism. Acta Crystallogr D Biol Crystallogr. 2014 Dec;70(Pt 12):3135-43.

21 Adams RH, Wilkinson GA, Weiss C, Diella F, Gale NW, Deutsch U, et al. Roles of ephrinB ligands and $\mathrm{EphB}$ receptors in cardiovascular development: demarcation of arterial/venous domains, vascular morphogenesis, and sprouting angiogenesis. Genes Dev. 1999 Feb; 13(3):295-306

22 Swift MR, Weinstein BM. Arterial-venous specification during development. Circ Res. 2009 Mar; 104(5):576-88.

23 Coultas L, Chawengsaksophak K, Rossant J. Endothelial cells and VEGF in vascular development. Nature. 2005 Dec;438(7070):937-45.

24 Wagenseil JE, Mecham RP. Vascular extracellular matrix and arterial mechanics. Physiol Rev. 2009 Jul;89(3):957-89.

25 Thoma R. Untersuchungen über die Histogenese und Histomechanikdes Gefässsytems. Stuttgart: Ferdinand Enke; 1893.

26 Hoffman BD, Grashoff C, Schwartz MA. Dynamic molecular processes mediate cellular mechanotransduction. Nature. 2011 Jul; 475(7356):316-23. 
27 Wang L, Zhang P, Wei Y, Gao Y, Patient R, Liu F. A blood flow-dependent klf2a-NO signaling cascade is required for stabilization of hematopoietic stem cell programming in zebrafish embryos. Blood. 2011 Oct; 118(15):4102-10

28 Udan RS, Vadakkan TJ, Dickinson ME. Dynamic responses of endothelial cells to changes in blood flow during vascular remodeling of the mouse yolk sac. Development. 2013 Oct;140(19):4041-50.

29 Seki T, Yun J, Oh SP. Arterial endotheliumspecific activin receptor-like kinase 1 expression suggests its role in arterialization and vascular remodeling. Circ Res. 2003 Oct; 93(7):682-9.

30 Fischer A, Schumacher N, Maier M, Sendtner M, Gessler M. The Notch target genes Heyl and Hey2 are required for embryonic vascular development. Genes Dev. 2004 Apr; 18(8):901-11.

31 Shin D, Anderson DJ. Isolation of arterialspecific genes by subtractive hybridization reveals molecular heterogeneity among arterial endothelial cells. Dev Dyn. 2005 Aug; 233(4):1589-604.

32 Mukouyama YS, Shin D, Britsch S, Taniguchi M, Anderson DJ. Sensory nerves determine the pattern of arterial differentiation and blood vessel branching in the skin. Cell. 2002 Jun;109(6):693-705.

33 Shutter JR, Scully S, Fan W, Richards WG, Kitajewski J, Deblandre GA, et al. Dll4, a novel Notch ligand expressed in arterial endothelium. Genes Dev. 2000 Jun;14(11):1313-8.

34 Yoshikawa SI, Aota S, Shirayoshi Y, Okazaki $\mathrm{K}$. The ActR-I activin receptor protein is expressed in notochord, lens placode and pituitary primordium cells in the mouse embryo. Mech Dev. 2000 Mar;91(1-2):439-44.

35 Villa N, Walker L, Lindsell CE, Gasson J, Iruela-Arispe ML, Weinmaster G. Vascular expression of Notch pathway receptors and ligands is restricted to arterial vessels. Mech Dev. 2001 Oct;108(1-2):161-4.

36 Lu X, Le Noble F, Yuan L, Jiang Q, De Lafarge $\mathrm{B}$, Sugiyama D, et al. The netrin receptor UNC5B mediates guidance events controlling morphogenesis of the vascular system. $\mathrm{Na}-$ ture. 2004 Nov;432(7014):179-86.

37 Leimeister C, Externbrink A, Klamt B, Gessler $M$. Hey genes: a novel subfamily of hairy- and enhancer of split related genes specifically expressed during mouse embryogenesis. Mech Dev. 1999 Jul;85(1-2):173-7.

38 Adams LD, Geary RL, McManus B, Schwartz SM. A comparison of aorta and vena cava medial message expression by cDNA array analysis identifies a set of 68 consistently differentially expressed genes, all in aortic media. Circ Res. 2000 Sep;87(7):623-31.

39 Zhou Y, Williams J, Smallwood PM, Nathans J. Sox7, Sox 17, and Sox 18 cooperatively regulate vascular development in the mouse retina. PLoS One. 2015 Dec;10(12):e0143650.
40 Benjamin LE, Hemo I, Keshet E. A plasticity window for blood vessel remodelling is defined by pericyte coverage of the preformed endothelial network and is regulated by PDGF-B and VEGF. Development. 1998 May;125(9):1591-8.

41 Spagnoli LG, Pietra GG, Villaschi S, Johns LW. Morphometric analysis of gap junctions in regenerating arterial endothelium. Lab Invest. $1982 \mathrm{Feb}$;6(2):139-48.

42 Devic E, Rizzoti K, Bodin S, Knibiehler B, Audigier Y. Amino acid sequence and embryonic expression of msr/apj, the mouse homolog of Xenopus X-msr and human APJ. Mech Dev. 1999 Jun;84(1-2):199-203.

43 Herzog Y, Kalcheim C, Kahane N, Reshef R, Neufeld G. Differential expression of neuropilin-1 and neuropilin-2 in arteries and veins. Mech Dev. 2001 Nov;109(1):115-9.

44 Morgan SM, Samulowitz U, Darley L, Simmons DL, Vestweber D. Biochemical characterization and molecular cloning of a novel endothelial-specific sialomucin. Blood. 1999 Jan;93(1):165-75.

45 Kaipainen A, Korhonen J, Mustonen T, van Hinsbergh VW, Fang GH, Dumont D, et al. Expression of the fms-like tyrosine kinase 4 gene becomes restricted to lymphatic endothelium during development. Proc Natl Acad Sci U S A. 1995 Apr;92(8):3566-70.

46 Moyon D, Pardanaud L, Yuan L, Bréant C, Eichmann A. Plasticity of endothelial cells during arterial-venous differentiation in the avian embryo. Development. 2001 Sep; 128(17):3359-70

47 Vihanto MM, Vindis C, Djonov V, Cerretti DP, Huynh-Do U. Caveolin-1 is required for signaling and membrane targeting of EphB1 receptor tyrosine kinase. J Cell Sci. 2006 Jun; 119(Pt 11):2299-309.

48 Lü P, Jiao Q, Shimura D, Kusakari Y, Liu F, Minamisawa S. Distinct vascular remodeling pattern of adult rats with carotid-jugular shunt. Ann Vasc Surg. 2018 May;49:168-78.

49 Bai H, Guo J, Liu S, Guo X, Hu H, Wang T, et al. Autologous tissue patches acquire vascular identity depending on the environment. Vasc Investig Ther. 2018 Apr-Jun;1(1):14-23.

50 Masood R, Xia G, Smith DL, Scalia P, Still JG, Tulpule A, et al. Ephrin B2 expression in Kaposi sarcoma is induced by human herpesvirus type 8: phenotype switch from venous to arterial endothelium. Blood. 2005 Feb; 105(3):1310-8.

51 Li X, Zhang X, Leathers R, Makino A, Huang C, Parsa $\mathrm{P}$, et al. Notch3 signaling promotes the development of pulmonary arterial hypertension. Nat Med. 2009 Nov; 15(11):1289-97.

52 Protack CD, Foster TR, Hashimoto T, Yamamoto K, Lee MY, Kraehling JR, et al. Eph-B4 regulates adaptive venous remodeling to improve arteriovenous fistula patency. Sci Rep. 2017 Nov;7(1):15386.
53 Wang M, Collins MJ, Foster TR, Bai H, Hashimoto T, Santana JM, et al. Eph-B4 mediates vein graft adaptation by regulation of endothelial nitric oxide synthase. J Vasc Surg. 2017 Jan;65(1):179-89.

54 Kertesz N, Krasnoperov V, Reddy R, Leshanski L, Kumar SR, Zozulya S, et al. The soluble extracellular domain of EphB4 (sEphB4) antagonizes EphB4-EphrinB2 interaction, modulates angiogenesis, and inhibits tumor growth. Blood. 2006 Mar;107(6):2330-8.

55 Yang C, Guo Y, Jadlowiec CC, Li X, Lv W, Model LS, et al. Vascular endothelial growth factor-A inhibits EphB4 and stimulates deltalike ligand 4 expression in adult endothelial cells. J Surg Res. 2013 Jul;183(1):478-86.

56 Muto A, Yi T, Harrison KD, Dávalos A, Fancher TT, Ziegler KR, et al. Eph-B4 prevents venous adaptive remodeling in the adult arterial environment. J Exp Med. 2011 Mar; 208(3):561-75.

57 Li X, Jadlowiec C, Guo Y, Protack CD, Ziegler $\mathrm{KR}, \mathrm{Lv} \mathrm{W}$, et al. Pericardial patch angioplasty heals via an Ephrin-B2 and CD34 positive cell mediated mechanism. PLoS One. 2012; 7(6):e38844.

58 Bai $\mathrm{H}$, Wang $\mathrm{M}$, Foster $\mathrm{TR}, \mathrm{Hu} \mathrm{H}, \mathrm{He} \mathrm{H}$, Hashimoto T, et al. Pericardial patch venoplasty heals via attraction of venous progenitor cells. Physiol Rep. 2016 Jun;4(12):e12841.

59 Li X, Dardik A, Guo R, Zhang W, Xiang Y, Li $S$, et al. Atorvastatin regulates pericardial patch healing via the microRNA140-ADAM10-ephrinB2 pathway. Am J Transl Res. 2018 Dec;10(12):4054-64.

60 Bai $\mathrm{H}, \mathrm{Hu} \mathrm{H}$, Guo J, Ige M, Wang T, Isaji T, et al. Polyester vascular patches acquire arterial or venous identity depending on their environment. J Biomed Mater Res A. 2017 Dec; 105(12):3422-31.

61 Buschmann I, Pries A, Styp-Rekowska B, Hillmeister P, Loufrani L, Henrion D, et al. Pulsatile shear and Gja5 modulate arterial identity and remodeling events during flow-driven arteriogenesis. Development. 2010 Jul; 137(13):2187-96

62 Liang TW, Jester A, Motaganahalli RL, Wilson MG, G'Sell P, Akingba GA, et al. Autologous bone marrow mononuclear cell therapy for critical limb ischemia is effective and durable. J Vasc Surg. 2016 Jun;63(6):1541-5.

63 Guo J, Guo L, Cui S, Tong Z, Dardik A, Gu Y. Autologous bone marrow-derived mononuclear cell therapy in Chinese patients with critical limb ischemia due to thromboangiitis obliterans: 10-year results. Stem Cell Res Ther. 2018 Feb;9(1):43.

64 Zamora DO, Davies MH, Planck SR, Rosenbaum JT, Powers MR. Soluble forms of EphrinB2 and EphB4 reduce retinal neovascularization in a model of proliferative retinopathy. Invest Ophthalmol Vis Sci. 2005 Jun; 46(6):2175-82. 
65 Calicchio ML, Collins T, Kozakewich HP. Identification of signaling systems in proliferating and involuting phase infantile hemangiomas by genome-wide transcriptional profiling. Am J Pathol. 2009 May;174(5):163849.

66 Dill MT, Rothweiler S, Djonov V, Hlushchuk $\mathrm{R}$, Tornillo L, Terracciano L, et al. Disruption of Notch1 induces vascular remodeling, intussusceptive angiogenesis, and angiosarcomas in livers of mice. Gastroenterology. 2012 Apr;142(4):967-77.e2.
67 Wang X, Adams LD, Pabón LM, Mahoney WM Jr, Beaudry D, Gunaje J, et al. RGS5, RGS4, and RGS2 expression and aortic contractibility are dynamically co-regulated during aortic banding-induced hypertrophy. J Mol Cell Cardiol. 2008 Mar;44(3):539-50.

68 Basu P, Qipshidze N, Tyagi SC, Sen U. Remodeling in vein expresses arterial phenotype in hyperhomocysteinemia. Int $\mathrm{J}$ Physiol Pathophysiol Pharmacol. 2011;3(4):266-79.

69 Hermanto Y, Takagi Y, Ishii A, Yoshida K, Kikuchi T, Funaki T, et al. Immunohistochemical analysis of Sox17 associated pathway in brain arteriovenous malformations. World Neurosurg. 2016 Mar;87:573-2.
70 Bai J, Wang YJ, Liu L, Zhao YL. Ephrin B2 and EphB4 selectively mark arterial and venous vessels in cerebral arteriovenous malformation. J Int Med Res. 2014 Apr;42(2):405-15.

71 Chennakesava CS, Di Santo S, Ziemiecki A, Schneider H, Andres AC. Differential expression of the receptor tyrosine kinase EphB4 and its ligand Ephrin-B2 during human placental development. Placenta. 2006 Sep-Oct; 27(9-10):959-67. 